\title{
Cameron, Deborah. and Shaw, Sylvia. (2016). Gender, Power and Political Speech: Women and Language in the 2015 UK General Election. Basingstoke Palgrave Macmillan. ISBN 978-1-137-58751-0
}

\section{Deborah Cameron and Sylvia Shaw's (2016) monograph Gender, Power and Political}

Speech: Women and Language in the 2015 UK General Election seeks to explore the language used both by and about female party leaders in the 2015 UK general election. In the 2015 general election, there were seven main parties, three of which were led by female politicians. A unique feature of this general election was that all parties were invited to televised debates. Eventually, there were two televised debates. One debate hosted all seven party leaders (broadcast on the BBC) and one 'challengers' debate (held on ITV), where political parties who were not part of the 2010-2015 government coalition between Conservative and Liberal Democrats were invited. Cameron and Shaw's analysis revolves these debates.

The monograph is both well written and structured logically, with the first chapter providing an insight into how women are viewed in the political sphere. Cameron and Shaw cover not only ideologies towards how women 'should' speak (for example, see Cameron, 2007) but also how female politicians use language (for exampling, see Shaw 2002; 2006). The following two chapters, firstly examine how the female political leaders used speech styles associated with masculinity and femininity to control the floor and challenge opponents. Secondly, in the third chapter, Cameron and Shaw explore the representation of the leaders in the media and how the media reported on the women's performances within the debates. Finally, the authors conclude the book by addressing important questions raised in the introduction: namely, “is there a 'different' voice employed by female politicians?".

The first chapter of analysis specifically examines the linguistic styles of not only the three female politicians but also their male counterparts in both the BBC and ITV debates. Cameron and Shaw go beyond simply asking 'who spoke more?' in the debate; they explore a range of linguistic practices such as turn taking, invited interruptions, and uninvited interruptions. Not only do they explore the frequencies at which they occur, but Cameron and Shaw give a nuanced analysis of how they are used and for what purposes. This chapter draws nicely on 'folk' ideologies of language and gender and considers the data through the lens of how every day non-academic people think women both should and do speak. Interestingly though, a repeated finding of the authors appeared to be that, although the 
female politicians would use some features associated with masculine speech styles, ultimately gender had little influence as a factor. Indeed, it appears political affiliation and the conflicting ideologies with those also on stage may account for the linguistic strategies used by the female leaders.

While transcripts can be 'messy', Cameron and Shaw provide a transparent and strong critical analysis of the turns and the functions of each turn. The chapter combines quantitative figures of turns taken as well as the functions of these turns with qualitative critical analysis of excerpts. The distinction between 'invited' and 'uninvited' turns helps shape the analysis and contextualises why certain factors may (or may not) occur. For example, one candidate was provided with fewer invited turns, which may be because she took more uninvited turns. The authors are able to contextualise the data and provide plausible explanations for their findings.

A range of previous literature has argued that the media shapes public opinion (for example, Gupta, 2015). Cameron and Shaw take this idea and examine how the media used language about the political leaders. The 219 texts subject to analysis within this section were gathered via Nexis and were then manually analysed. Ultimately, as one may suspect, there were sexist remarks about the women, but two of the three female leaders were still seen as legitimate threats. The authors draw on Kanter's (1993) work and suggest women were represented in one of four archetypical ways: as a mother, a seductress, an iron maiden, or a pet. These archetypes are highlighted via detailed critical analysis of excerpts. Chapter three demonstrates that there is a still a bias against women in the political sphere and what is said about them rests on culturally gendered stereotypes. In comparison to chapter 2 , the authors note that the 'women's voice' ideology was more present in the reception by the press than it was produced by the female leaders. The comparisons made at the end of chapter 3 tie both chapters together nicely and provide a useful overview of usage in comparison to representation.

In terms of the methodology employed, although manual analysis of the texts is not an issue, the analysis in this section may have benefited from triangulation with analysis via corpus linguistic methods. A large amount of research which has utilised texts from Nexis have relied on corpus linguistic methods (for example, Baker, 2012). Indeed, it would have been interesting to compare the statistically significant collocates of the female politicians 
with themes which emerged from manual analysis. This method could have opened different routes of analysis which would be interesting to cross compare.

The monograph concludes by recapping the previous chapters and answering a question first asked by the authors: "do women use 'a different voice' in the data?". The authors express that although gender may have had some effect, and indeed this is something which the headlines claimed, the combination of factors contributed to the women's speech styles. In this final chapter, the authors explore how the women were received and compare it to how the male political leaders were viewed, via an analysis of when the audience laughed and applauded, as well as by referring to political opinion polls. Finally, Cameron and Shaw analyse how the most prominent of the three female politicians, Nichola Sturgeon, was received by the public and what factors, not just gender, may have influenced how she was perceived. The authors argue that gender was just one of many factors in her performance, and although it was often backgrounded it was still present and contributed to how she was perceived.

Altogether, this monograph draws on multiple threads: political discourse analysis, gender, and critical media analysis. Cameron and Shaw were presented with a large topic, and so have elected to examine a case study, in order to do justice to the combination of the fields. The monograph is well-written and is easily accessible. Although the overview of the research is less concerned with outlining the multiple caveats and gaps within all the fields individually, the authors provide enough of an overview so as readers who are unfamiliar with any one field may an insight to appreciate the application of linguistic analysis to this case study. There are a few potential areas where additional research could compliment the work undertaken by the authors, such as using corpus approaches to the data, exploring the representation of the female politicians on social media, or comparing the data to the speech styles of female politicians in other countries in greater depth. Nevertheless, Cameron and Shaw's work is a much welcome addition to the fields of critical political discourse analysis and gendered discourse analysis.

\section{References:}

Baker, Paul. (2012). Acceptable bias? Using corpus linguistics methods with critical discourse analysis. Critical discourse studies, 9 (3), pp.247-256.

Cameron, Deborah. (2007). The Myth of Mars and Venus. Oxford: Oxford University Press. 
Cameron, Deborah. and Shaw, Sylvia. (2016). Gender, Power and Political Speech: Women and Language in the 2015 UK General Election. Basingstoke: Palgrave Macmillan.

Gupta, Kat. (2015). Representation of the British Suffrage Movement. London: Bloomsbury.

Kanter, Rosabeth. (1993). Men and women of the corporation (2nd ed.). New York, NY:

Basic Books.

Shaw, Sylvia. (2002). Language and gender in political debates in the House of

Commons. PhD thesis. The Institute of Education, University of London.

Shaw, Sylvia. (2006). Governed by the rules? The female voice in parliamentary debates. in:

Baxter, Judith. (ed.) Speaking out: the female voice in public contexts. Basingstoke: Palgrave Macmillan. pp. 81-102. 